\title{
Corrosive injury of the stomach: an unusual presentation
}

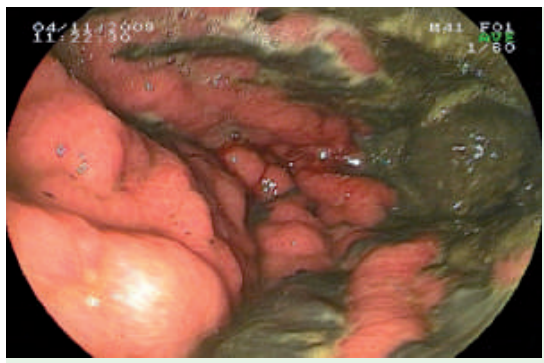

Fig. 1 Endoscopic view showing multiple linear ulcers, covered with slough, in the body of the stomach, becoming confluent distally in the antrum.

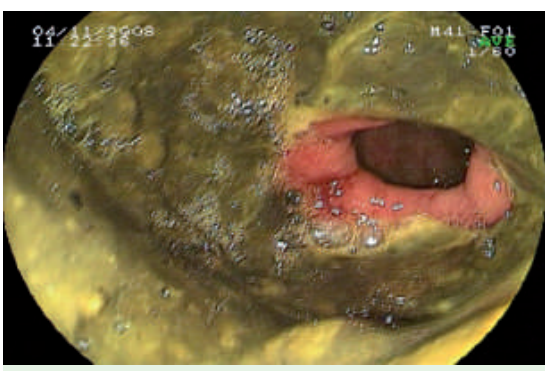

Fig. 2 Circumferential antral ulcer with slough, sparing the pyloric orifice.

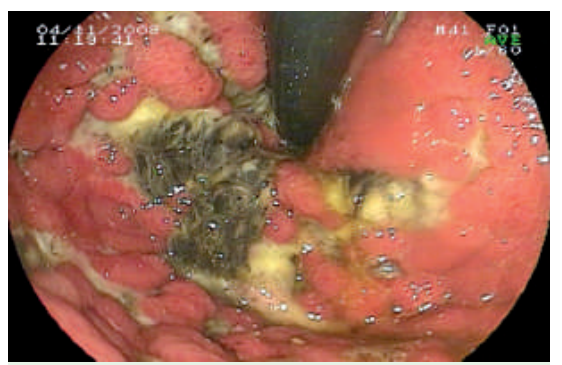

Fig. 3 Retroflexed endoscopic view shows multiple linear ulcers involving the fundus and covered with slough.

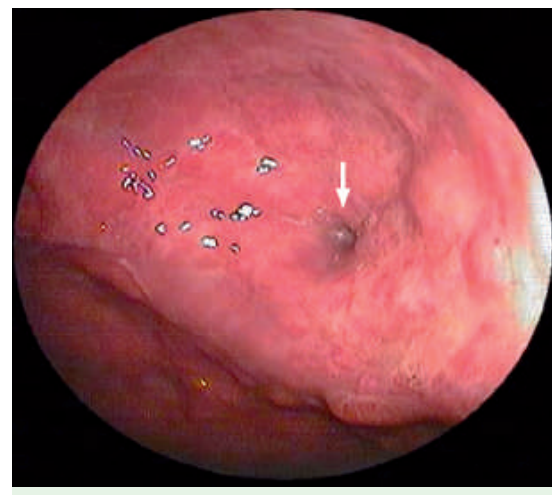

Fig. 4 Deformed antrum with a stricture seen as a small opening in the middle (white arrow).

supportively with sucralfate. The patient presented 4 weeks later with persistent vomiting. A repeat endoscopy showed an antral stricture ( $\bullet$ Fig. 4). At the time of writing, the patient was awaiting surgery. Corrosive ingestion is a common cause of benign strictures of the upper aero-digestive tract in India. Hydrochloric acid, which is commonly available as a toilet cleaning agent, is the most common corrosive substance ingested [1]. Corrosive injury after ingestion of country liquor has been reported from India [2]. Our patient denied consumption of acid. The evidence of corrosive injury to the stomach complicated by an outlet obstruction within a period of 4 weeks clearly suggests that the "country liquor" (cheap crudely made alcohol) was probably contaminated with some acid. Alternatively, the possibility that the patient had consumed acid in an inebriant state cannot be totally dismissed. An awareness of corrosive injury on a background of alcohol consumption needs to be considered in patients presenting with massive gastrointestinal bleeding with classical endoscopic findings.

Endoscopy_UCTN_Code_CCL_1AB_2AD_3AF

\section{A. Somasundaram, R. Ravi, J. Venkataraman}

Department of Gastroenterology, Stanley Medical College, Chennai, India

\section{References}

1 Zargar SA, Kochhar R, Nagi B et al. Ingestion of corrosive acids. Spectrum of injury to upper gastrointestinal tract and natural history. Gastroenterology 1989; 97: 702 - 707

2 Agarwal S, Sikora SS, Kumar A et al. Surgical management of corrosive strictures of the stomach. Indian J Gastroenterol 2004; 23 : $178-180$

Bibliography

DOI 10.1055/s-0029-1214440

Endoscopy 2009; 41: E92 -E92

(c) Georg Thieme Verlag KG Stuttgart · New York . ISSN 0013-726X

Corresponding author

A. Somasundaram, MD

Department of Gastroenterology

Stanley Medical College

Chennai

India 600081

Fax: +91-44-25953211

aravindhsom@gmail.com 